\title{
Frequency Characteristics and Numerical Computation of Seismic Records Generated by a Giant Debris Flow in Zhouqu, Western China
}

\author{
Xinghu Huang, ${ }^{1}$ Zhengyuan Li, ${ }^{1}$ (D) Junyi Fan, ${ }^{1}$ Dan Yu, ${ }^{1}$ and Qiang Xu ${ }^{2}$
}

\begin{abstract}
The catastrophic Sanyanyu and Luojiayu debris flows, which were induced by heavy rain, struck Zhouqu County in Gannan Prefecture, Gansu Province, at approximately midnight, 7 August 2010 (Beijing time, UTC +8 ), causing 1765 fatalities and huge economic loss. The ZHQ seismic station is located approximately $170 \mathrm{~m}$ west of the outlet of the Sanyanyu gully, and its power system was destroyed by the Sanyanyu debris flow when its leading edge reached the vicinity of the seismic station. In this paper, seismic signals recorded approximately $10 \mathrm{~min}$ before its termination are collected and analyzed to study the Sanyanyu debris flow. A double-exponential model is first proposed to quantitatively characterize seismic energy distributions in the frequency domain, which reveals that the peak frequency of seismic signals is around $5 \mathrm{~Hz}$. Influenced by the Doppler effect, the peak frequency of the N-S component is the highest, and the U-D component is the lowest. Time-frequency analysis is applied to the seismic signals. From the spectrogram, it is easily observed that the formation time of the Sanyanyu debris flow is around 23:33:10. The entire debris flow is divided into three phases with distinct frequency characteristics, using 23:36:20 and 23:37:35 as crucial times. The frequency energy distributions in the first two phases are relatively stable, and are constrained in $0-8.8 \mathrm{~Hz}$ and $0-17.8 \mathrm{~Hz}$, respectively. For the third phase, the upper boundary of frequency energy increases in a nearly linear manner, reaching approximately $35 \mathrm{~Hz}$ at the end. We calculate synthetic seismograms of the Sanyanyu debris flow. Generally, synthetic seismograms have morphological features and characteristics in key stages similar to those of the actual seismic records, and their maximum values are of the same magnitude. Our results suggest that the seismic source of a debris flow can be represented by a single-force model, and reveal that real-time monitoring and rapid identification of potential debris flows using broadband seismic network records is possible, which can provide approximately $15 \mathrm{~min}$ of pre-event warning for local residents and hopefully save many lives.
\end{abstract}

Key words: August 7 Zhouqu debris flows, broadband seismic signals, frequency characteristics, numerical computation.

1 China Earthquake Networks Center, Beijing, China. Email: precursor0216@126.com

2 State Key Laboratory of Geohazard Prevention and Geoenvironment Protection, Chengdu University of Technology, Chengdu, China.

\section{Introduction}

Most of western and southwest China is characterized by mountainous areas with dramatically varying terrain, resulting in extensive development of catastrophic natural geological hazards, such as landslides and debris flows, which seriously affect the lives of local residents (e.g., Cui et al. 2003; Zeng et al. 2014). Debris flows are generally induced by heavy rain. During a debris flow, mixtures containing water, debris, and loose sediment rush out of the outlet of a gully at a very high speed, carrying a large amount of material and energy, destroying cities and villages and causing widespread devastation. At present, studies on debris flows are mainly carried out after their occurrence, since they are usually unpredictable. They are also very destructive, and field measurement equipment is usually destroyed; thus data cannot be collected. Under these conditions, real-time monitoring and rapid identification of a potential debris flow is essential for enacting early warning protocols and enabling effective relief-andrescue operations.

Remote and continuous observations from seismic networks provide a novel and reliable means to quantitatively extract physical properties of flows on the earth's surface; for example, seismic records have been used to monitor river discharge (Burtin et al. 2008) and to study the formation of a barrier lake by landslides and the collapse of a dam (Feng 2012). Studies show that broadband seismic records also provide a good tool for extraction of key parameters of debris flows (e.g., Arattano 1999; Burtin et al. 2009). Characteristics of the seismic signals generated by debris flows have been researched in detail by physical experiments and field observations, which have shown that they are caused by the friction 
between the flowing material and the boundary and the collision between the flowing substances (e.g., Huang et al. 2004, 2007; Ekström and Stark 2013; Yamada et al. 2013). In addition, the predominant frequency of seismic signals is relatively high, resulting in rapid seismic energy attenuation (e.g., Huang et al. 2008; Burtin et al. 2009), and the seismic amplitude is proportional to the discharge of the debris flow (Huang et al. 2008). An early warning system for debris flows based on seismic network observations requires properties of seismic signals recorded very close to the events; however, near-field observations of debris flow signals are seldom reported.

In this paper, we analyze seismic signals generated by a giant debris flow and recorded on a seismic station very close to the event to extract their frequency characteristics. Subsequently, we calculate synthetic seismograms of the debris flow on the seismic station using a single-force seismic source model and configurations of the Sanyanyu gully, and compare the results with the recorded seismic signals. The frequency characteristics of the debris flow seismic signals and procedures for computing its synthetic seismograms presented here are expected to support early warning systems for debris flows based on seismic network observations.

\section{Zhouqu Debris Flows and Seismic Observations}

Heavy rain began in Zhouqu County on the night of 7 August 2010 (Beijing time, UTC +8 , used throughout this paper), with maximum hourly intensity of up to $77.3 \mathrm{~mm}$ (Yu et al. 2010). Debris flows induced by the heavy rainfall rushed out from the Sanyanyu and Luojiayu gullies, destroying a large number of buildings in Zhouqu County and causing 1765 fatalities. The total amount of sedimentary deposits accumulated by the debris flows was as large as $2.2 \times 10^{6} \mathrm{~m}^{3}$, most of which was deposited on the original alluvial fan, and a small part rushed into the Bailong River in front, forming a 9-m-high dam (Tang et al. 2011) and a 3-km-long barrier lake (Fang et al. 2010). Blocked by the newly formed dam, the water level of the Bailong River rose about $8 \mathrm{~m}$, and part of the water went over the bank into Zhouqu
County, causing further disasters (Yu et al. 2010; Tang et al. 2011).

The ZHQ seismic station is located approximately $170 \mathrm{~m}$ west of the outlet of the Sanyanyu gully, as shown in Fig. 1. The power system of the ZHQ station was destroyed by the Sanyanyu debris flow when its leading edge reached the outlet of the gully, marking the termination of the seismic records. However, before that, seismometers recorded the continuously varying waveforms, as shown in Fig. 2. The ZHQ seismic station is located very close to the outlet of the Sanyanyu gully, and more than 64\% of the sediments were from the Sanyanyu drainage basin, indicating that the seismic energy recorded by the station was mainly generated by the Sanyanyu debris flow. The length of the main channel in the Sanyanyu gully is $10.4 \mathrm{~km}$ and its basin area is $25.75 \mathrm{~km}^{2}$, as shown in Fig. 1. At an altitude of $1600 \mathrm{~m}$, the Sanyanyu gully is divided into two tributaries: the Dayanyu gully to the west and the Xiaoyanyu gully to the east. The maximum elevation at the source area is $3830 \mathrm{~m}$, and the minimum elevation near the outlet is $1340 \mathrm{~m}$. The slope is about $39^{\circ}$ at the source area and only $5.7^{\circ}$ in the sedimentary area, with an average of about $13.4^{\circ}$ (Tang et al. 2011).

\section{Seismic Signals Generated by the Sanyanyu Debris Flow}

\subsection{Frequency Characteristics of Seismic Signals}

The amplitude spectra of seismic signals in Fig. 2 are shown in Fig. 3. Unlike seismic signals generated by earthquakes and landslides, whose seismic energy is concentrated within the frequency band at less than $10 \mathrm{~Hz}$ (e.g., Deparis et al. 2008; Dammeier et al. 2011; Hibert et al. 2011; Kao et al. 2012; Chen et al. 2013), energy in the debris flow signals observed herein covers almost the entire frequency band, with peak frequencies at $\sim 5 \mathrm{~Hz}$. Before and after the peak frequency, the seismic energy increases and decreases exponentially, respectively, with different rates. We propose a model using the following equation to characterize the seismic energy distribution in the frequency domain: 


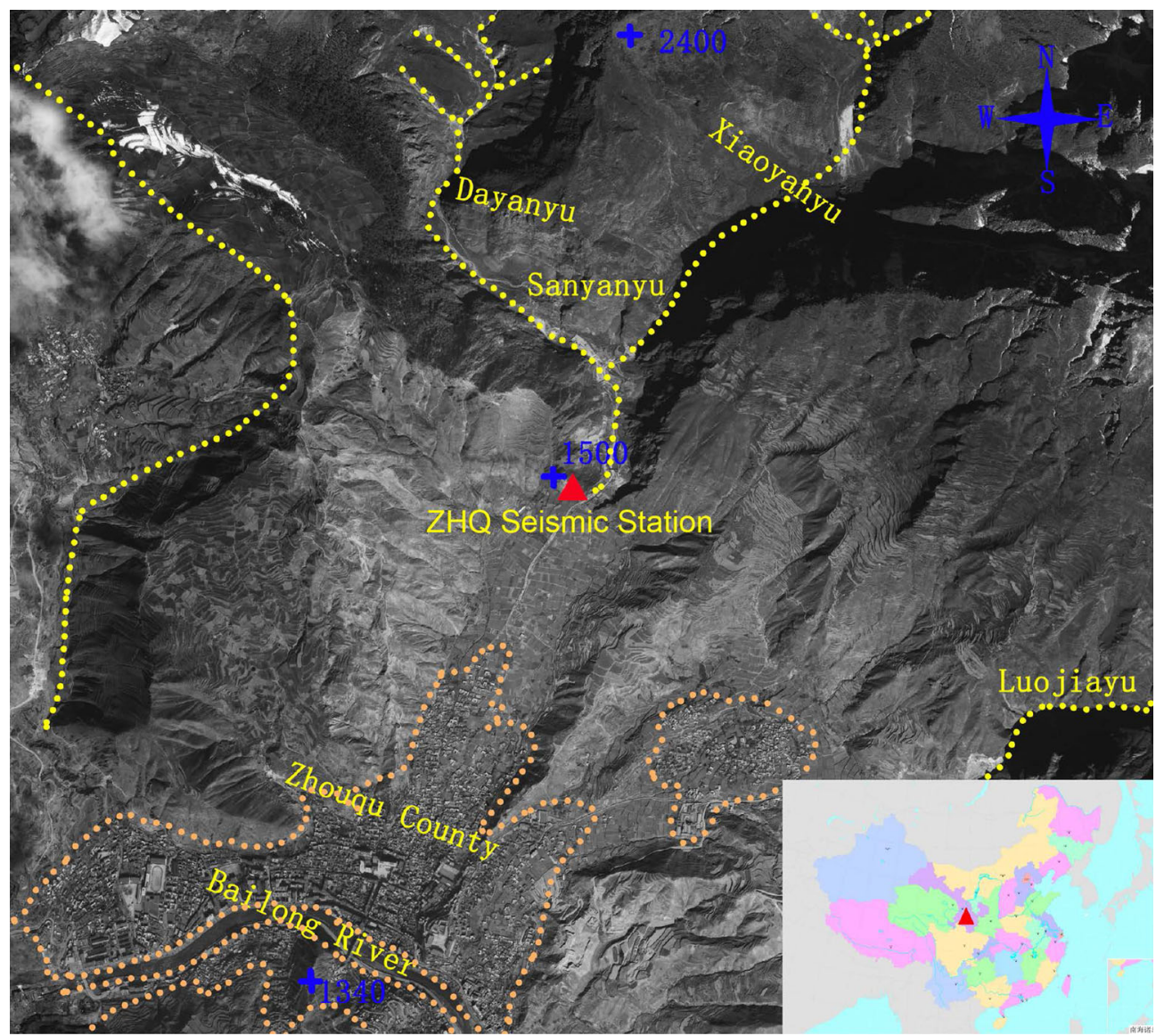

Figure 1

Locations of the ZHQ seismic station (red solid triangle), the Sanyanyu Gully, and the Luojiayu Gully

$$
a= \begin{cases}a_{0} \times e^{b_{1}\left(f-f_{\mathrm{p}}\right)} & f \leq f_{\mathrm{p}} \\ a_{0} \times e^{b_{\mathrm{r}}\left(f-f_{\mathrm{p}}\right)} & f>f_{\mathrm{p}}\end{cases}
$$

where $a_{0}$ is the peak amplitude, $f_{\mathrm{p}}$ is the peak frequency, and $b_{1}$ and $b_{\mathrm{r}}$ are the coefficients of the growth phase and the reduction phase, respectively. The best-fit coefficients for the three components are provided in Table 1. From the results, we observe that the peak frequency of the N-S component is the largest, the E$\mathrm{W}$ component is the second largest, and the U-D component is the smallest. We attribute this phenomenon to the Doppler effect. The movement of the Sanyanyu debris flow was mainly horizontal, and more specifically, from north to south. Therefore, the influence of the Doppler effect on the seismic record from strong to weak is the $\mathrm{N}-\mathrm{S}$ component, the E-W component, and the U-D component, respectively. Influenced by the Doppler effect, the relationship between the true frequency and its apparent value is:

$$
f_{\mathrm{obs}}=f_{\text {real }} \frac{v_{\mathrm{w}}+v_{\mathrm{m}}}{v_{\mathrm{w}}}
$$

where $f_{\text {obs }}$ is the observed frequency, $f_{\text {real }}$ is the true frequency, $v_{\mathrm{w}}$ is the wave propagation speed, and $v_{\mathrm{m}}$ is the movement speed of the signal source, the debris flow in this case. Taking a wave propagation speed of $100 \mathrm{~m} / \mathrm{s}$ (Arattano 1999) and a debris flow movement speed of $10 \mathrm{~m} / \mathrm{s}$ (Tang et al. 2011) allows us to obtain the $f_{\text {obs }} / f_{\text {real }}$ of $\sim 1.1$. Since the horizontal movement of the debris flow is much larger than its vertical movement, we assume that the influence of the 

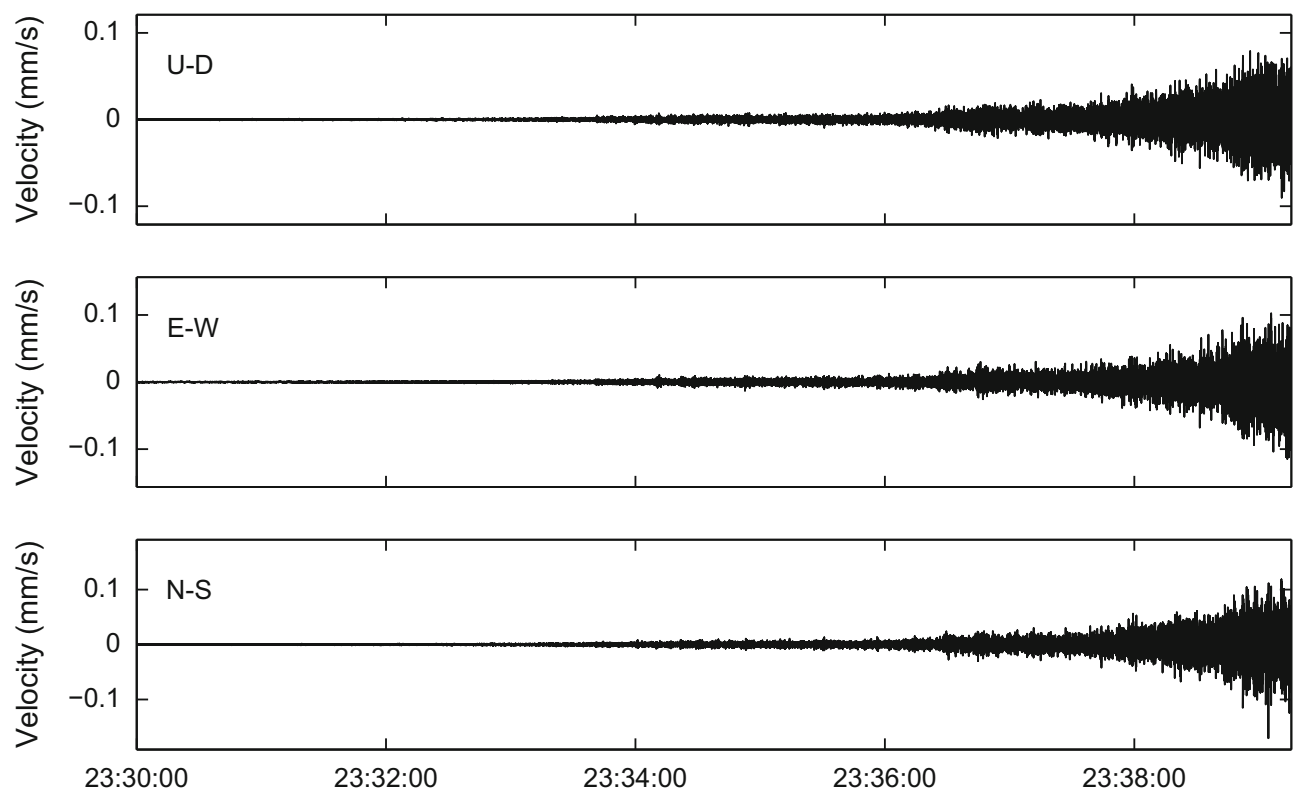

Figure 2

Seismic waveforms approximately 10 min before the power system of the ZHQ seismic station was destroyed by the Sanyanyu debris flow. Top to bottom, the images are U-D, E-W, and N-S components

Doppler effect on the U-D component is negligible, suggesting that the true peak frequency of debris flow signals can be approximated using $4.86 \mathrm{~Hz}$. Taking the observed peak frequency of $5.77 \mathrm{~Hz}$ for the N-S component, we obtain the observed $f_{\text {obs }} / f_{\text {real }}$ of 1.187 , which is in agreement with the theoretical result. The best-fit results also reveal that the peak amplitude of the N-S component is the largest, and the U-D component is the smallest, indicating the influence of the movement direction of the debris flow on the seismic signals.

\subsection{Stages of the Sanyanyu Debris Flow Revealed by Seismic Signals}

The spectrogram of the U-D component seismic signal was acquired using the short-time Fourier transform, as shown in Fig. 4. From the spectrogram we observe that the effective signal starts at approximately 23:33:10. Before this time, the seismic amplitude is small and the peak frequency is low, showing characteristics of background signal. Seismic signals after this time can be further divided into three stages. The first stage is from 23:33:10 to
23:36:20, with a stable main frequency within $8.8 \mathrm{~Hz}$. The second stage is to 23:37:35, with a stable main frequency within $17.8 \mathrm{~Hz}$. Seismic signals from 23:37:35 to the end constitute the last stage. During this stage, the upper boundary of main frequency increases linearly to $\sim 35 \mathrm{~Hz}$. The main frequency band of seismic signals extends to a higher frequency with time, showing characteristics of an approaching seismic source, as the high-frequency seismic energy decays rapidly, and a higher frequency corresponds to a shorter propagation distance.

\subsection{Possible Precursors of the Debris Flow}

Seismic signals from 22:30:00 to 23:33:10 were selected to study the precursors of the debris flow. The waveforms are shown in Fig. 5. We observe that seismic signals during this period have two obvious features. First, the seismic amplitude begins to increase substantially from about 23:24:00, indicating that the debris flow started accumulating material and kinetic energy, since the seismic amplitude of a debris flow is proportional to its discharge (Huang et al. 2008). Second, the seismic records detect a 

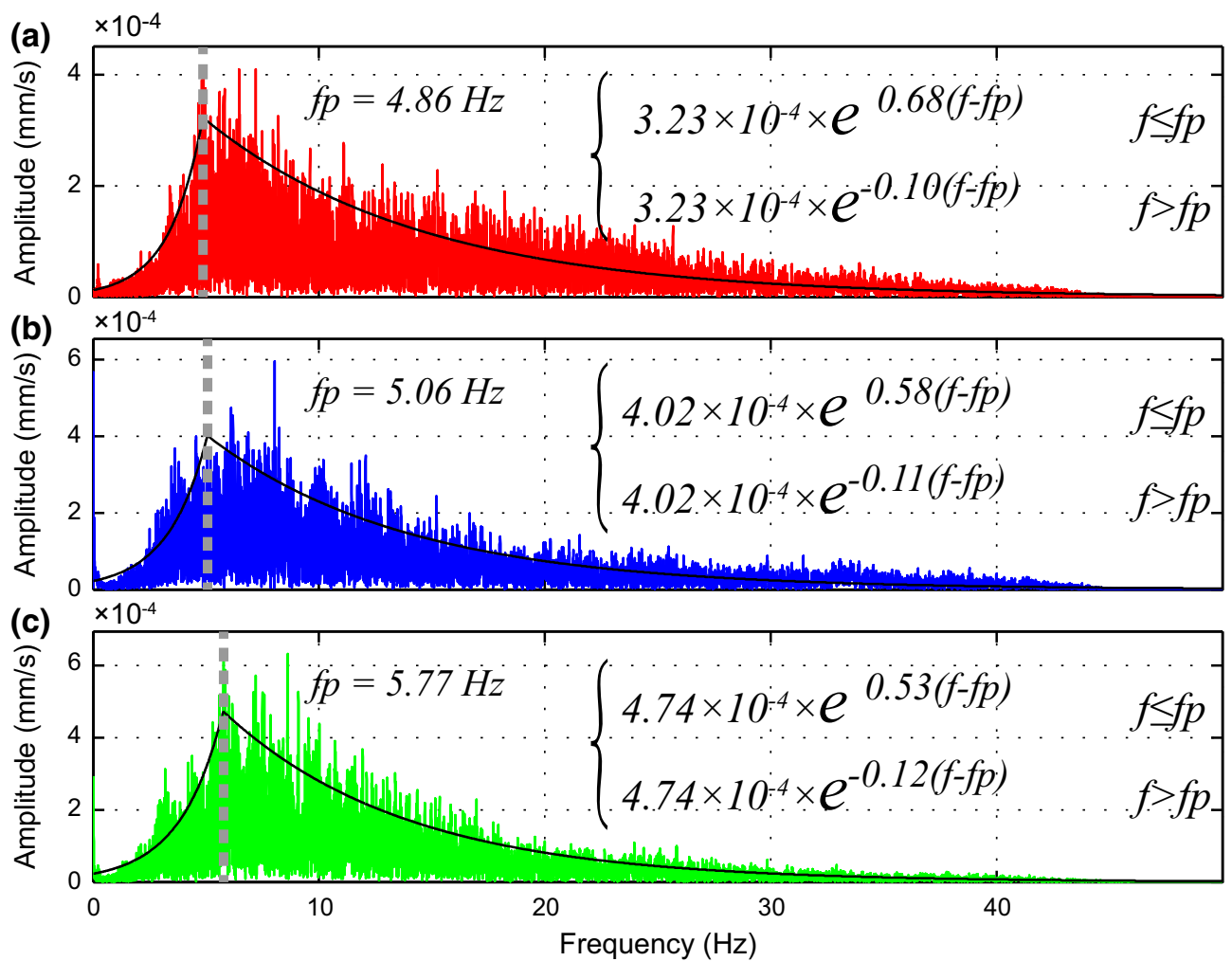

Figure 3

Frequency amplitude spectrum of three components. From top to bottom, images are U-D component, E-W component, and N-S component. Black solid lines are best-fit double-exponential models; gray dashed lines are positions of peak frequencies

Table 1

Best-fit coefficients of energy distribution model in frequency domain for three components

\begin{tabular}{lllll}
\hline Component & $a_{0}(\mathrm{~mm} / \mathrm{s})$ & $f_{\mathrm{p}}$ & $b_{1}$ & $b_{\mathrm{r}}$ \\
\hline U-D & $3.23 \times 10^{-4}$ & 4.86 & 0.68 & -0.10 \\
E-W & $4.02 \times 10^{-4}$ & 5.06 & 0.58 & -0.11 \\
N-S & $4.74 \times 10^{-4}$ & 5.77 & 0.53 & -0.12 \\
\hline
\end{tabular}

series of signal spikes starting at about 22:50:00. Although the location of the events related to the spikes cannot be determined using seismic records from only one seismic station, the spectrogram of the signal spikes shown in Fig. $6 \mathrm{~b}$ indicates that they occurred very close to the seismic station, as their seismic energy exhibits very wide frequency content, covering almost the entire frequency range (i.e. 0-50 Hz), and high-frequency seismic signals decay rapidly (e.g., Toksöz and Johnston 1981; Huang et al.
2008; Burtin et al. 2009). In addition, the frequency content of the spike signals are very similar to seismic signals generated by rock collapses that were recorded within hundreds of meters (Vilajosana et al. 2008), indicating that the spikes were most likely generated by rock falls within the Sanyanyu catchment and induced by the rain. These two features could be used for early identification of a potential debris flow and issuance of warnings. 


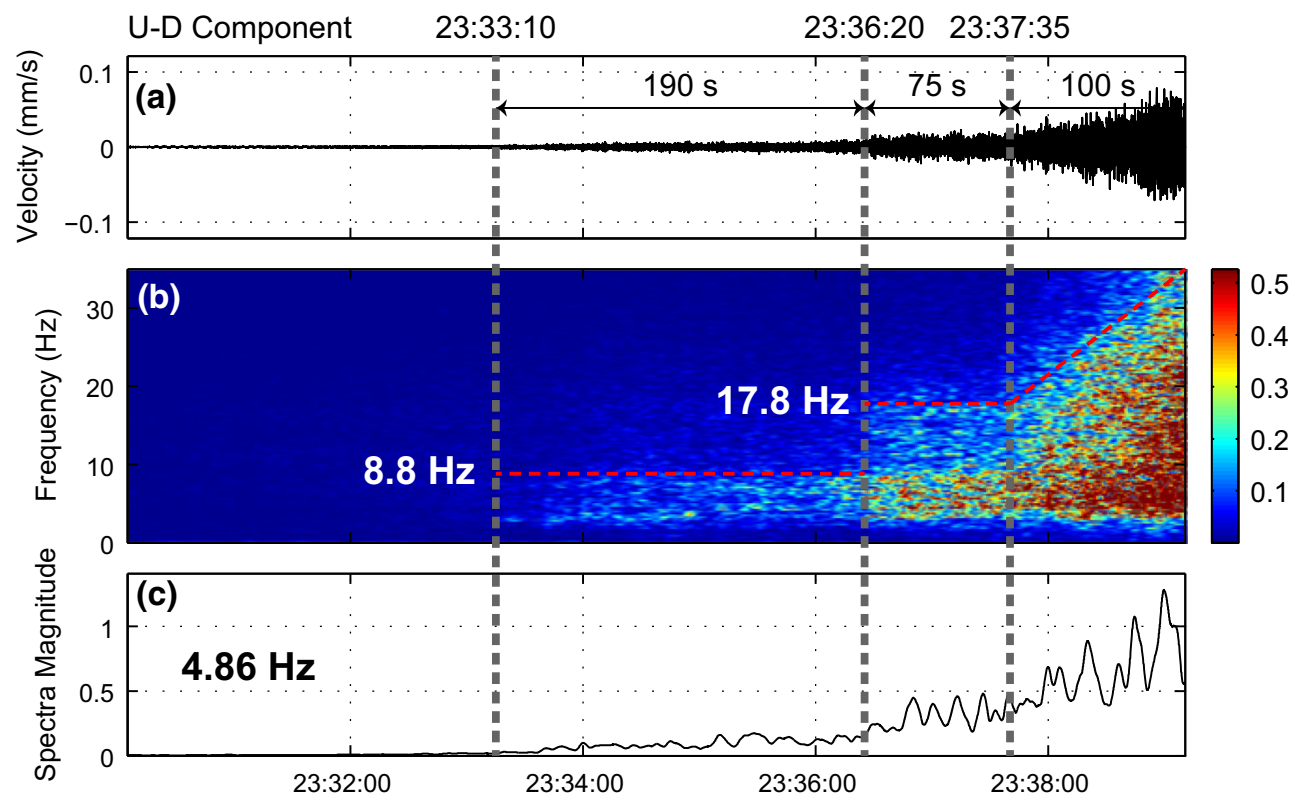

Figure 4

a Seismic waveform of the U-D component. b Spectrogram of the signal. c Amplitude along the peak frequency from the spectrogram. Gray dashed lines depict the formation time and crucial times of the Sanyanyu debris flow. Red dashed lines depict the upper boundaries of effective signals for different phases
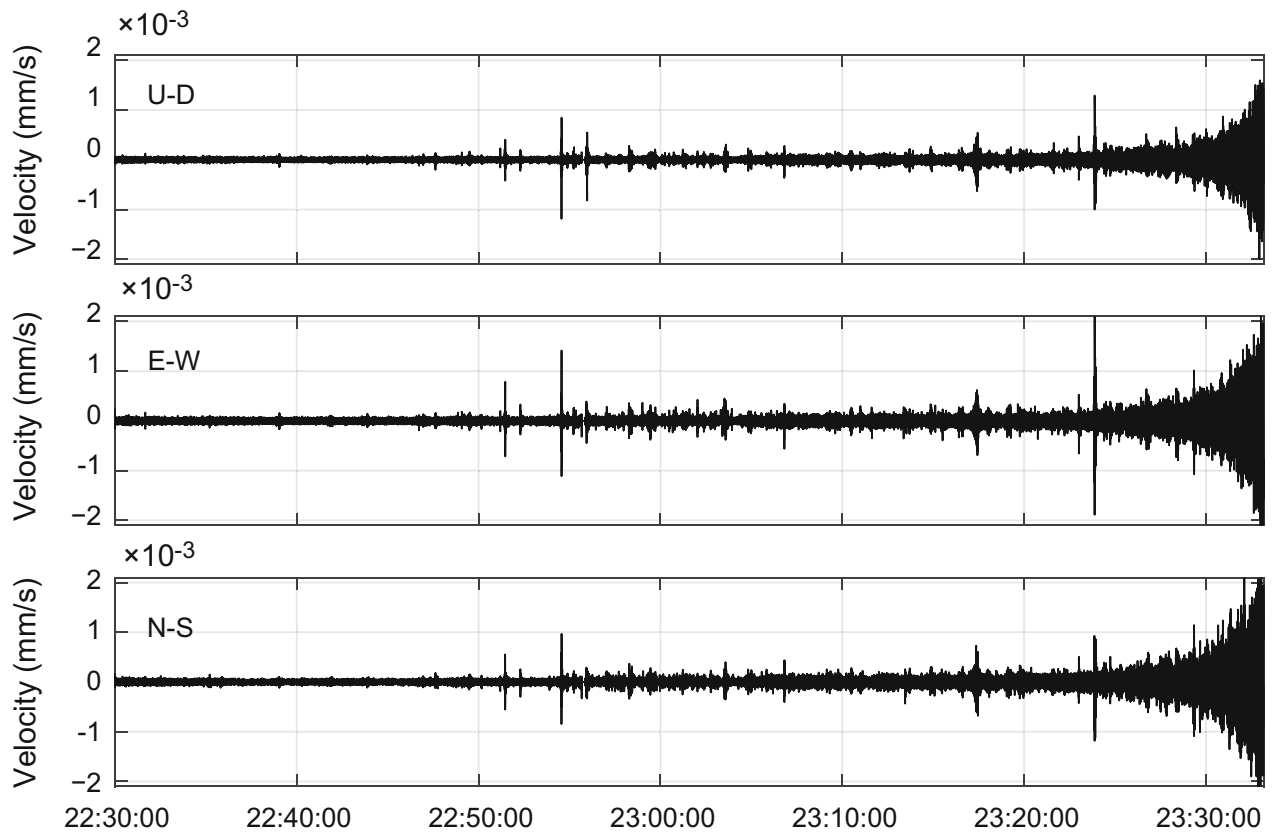

Figure 5

Seismic waveforms before the formation of the debris flow 

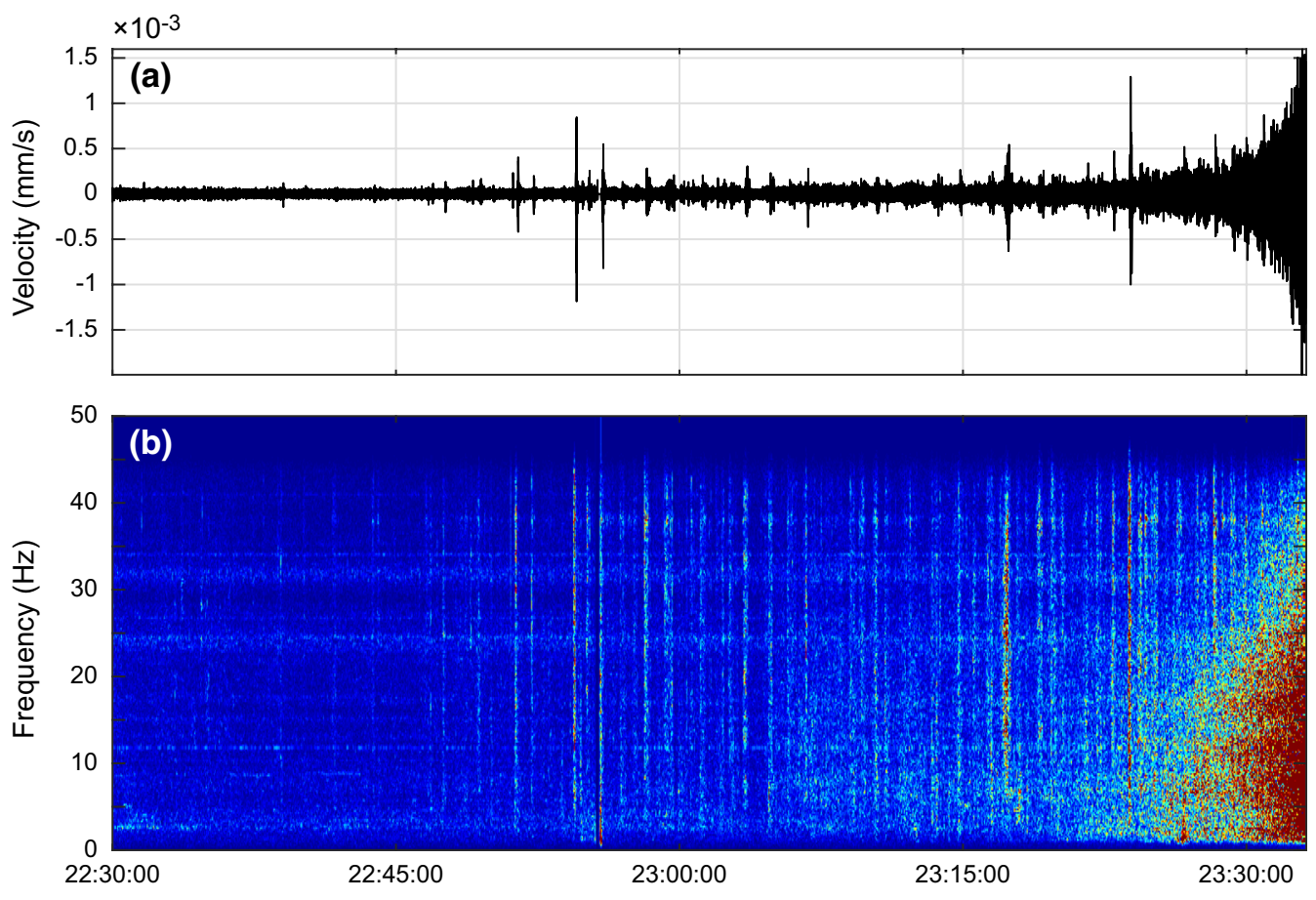

Figure 6

a U-D component seismic waveform before the formation of the debris flow. b Spectrogram of the seismic signals in a

\section{Numerical Computations}

\subsection{Source Representation of a Debris Flow}

It is generally agreed that the earthquake source can be represented by the double-couple model (Aki and Richards 2002). For movements on the earth's surface, such as landslides, debris flows, and glacier avalanches, the seismic source is better represented by a single-force (SF) model (e.g., Kanamori and Given 1982; Kanamori et al. 1984; Hasegawa and Kanamori 1987; Dahlen 1993; Fukao 1995; Ekström et al. 2003). Based on the analyses of a slope-slide model, the three component forces applied to the crust by a landslide or a debris flow can be expressed as (e.g., Zhao et al. 2015):

$$
\begin{aligned}
& f_{x}=m g \cos \theta(\mu \cos \theta-\sin \theta) \sin \varphi, \\
& f_{y}=m g \cos \theta(\mu \cos \theta-\sin \theta) \cos \varphi, \\
& f_{z}=m g \cos \theta(\mu \sin \theta+\cos \theta)-m g,
\end{aligned}
$$

where $m$ is the mass of flowing material, $g$ is the gravitational acceleration, $\theta$ is the slope along the flow path, $\mu$ is the dynamic frictional coefficient, and $\varphi$ is the azimuth of the flow direction. The forces are mainly composed of two parts: the body force associated with the gravity and the frictional force generated along the slip surface. Previous studies have shown that the seismic signals generated by landslides and debris flows can be divided into highfrequency components and low-frequency components. The high-frequency components are mainly caused by the friction between the sliding material and the surroundings and collisions within the sliding material (e.g., Ekström and Stark 2013; Yamada et al. 2013; Hibert et al. 2014); while the low-frequency component characterizes unloading and reloading processes of the crust caused by acceleration and deceleration of the sliding mass (e.g., Li et al. 2017). The amplitude spectrum of the seismic signal generated by the Sanyanyu debris flow is shown in Fig. 3. It can be observed that the predominant frequency is relatively high, approximately $5-10 \mathrm{~Hz}$, and the low-frequency energy is weak, which is consistent with previous studies (e.g., Huang et al. 
2008), indicating that the unloading and reloading of the crust is not obvious throughout the entire process of the debris flow, and the speed of the debris flow is relatively stable. Therefore, we use only the friction [the terms with the frictional coefficient in Eqs. (3)(5)] as seismic sources of the debris flows in calculating synthetic seismograms. The synthetic seismograms can be expressed as a convolution of source time functions and Green's functions. For given locations of a seismic source and seismic stations and a single-force representation of seismic source, the synthetic seismic records can be expressed as follows:

$$
s_{m}(j \Delta t)=\sum_{i=1}^{3} \sum_{l=0}^{n t-1} G_{i m}(j \Delta t-l \Delta t) f_{i}(l \Delta t) \Delta t,
$$

where $\Delta t$ is the time sampling interval, $s_{m}$ is the $m$ th seismic record, $f_{i}$ is the $i$ th component unit force, and $G_{i m}$ is Green's function of $f_{i}$ to $s_{m}$, calculated using the matrix propagation method (Wang 1999). The velocity model is derived from Crust1.0. In calculating synthetic seismograms of a landslide, the seismic source is generally assumed to be a point source at a fixed location (e.g., Ekström and Stark 2013; Hibert et al. 2014; Li et al. 2017; Huang et al. 2018). This assumption is satisfied when the epicentral distance of the seismic stations is much larger than the spatial range of the landslide. Under this assumption, the seismic source is only a function of time, which can greatly simplify the calculation. However, the spatial scale of the debris flows is too large to be ignored compared with the distances between the event and seismic stations, indicating that the source can no longer be treated as a fixed source. Therefore, we use a moving point source model for the debris flow in the calculation.

\subsection{Synthetic Seismograms for the Sanyanyu Debris Flow}

Synthetic seismograms for the Sanyanyu debris flow are calculated using the shape of the flow path, the altitude, and slope along the channel provided in Fig. 7a-c, respectively. Field investigations found that the total volume of sedimentary deposits accumulated by the debris flows was about 2.2 million $\mathrm{m}^{3}$, and $64 \%$ came from the Sanyanyu drainage basin. Therefore, the mass of the Sanyanyu debris flow was about $3.24 \times 10^{9} \mathrm{~kg}$, assuming a debris flow density of $2.3 \times 10^{3} \mathrm{~kg} / \mathrm{m}^{3}$. This total volume of sedimentary deposits was accumulated during several tens of minutes, and in the process of the Sanyanyu debris flow, the mass was only part of it. In addition, the mass of the flowing material was continuously increasing due to entrainment of sedimentary material. Therefore, we construct a mass model for the Sanyanyu debris flow in which the mass increases exponentially from $6.5 \times 10^{4} \mathrm{~kg}$ at the beginning to $6.5 \times 10^{5} \mathrm{~kg}$ at the end. The velocity of the debris flow is assumed to be $10 \mathrm{~m} / \mathrm{s}$ in the calculation based on estimations using empirical equations (Tang et al. 2011). Synthetic seismograms for the Sanyanyu debris flow are shown in Fig. 8.

Figures 2 and 8 reveal that synthetic seismograms and actual seismic records have similar amplitude variation characteristics, i.e. they increase in approximately an exponential manner with time and finally reach around $0.1 \mathrm{~mm} / \mathrm{s}$. These characteristics are partly related to the shape of the debris flow channel and partly caused by the increase in the mass of the flowing material. Field seismic records show that seismic amplitude began to increase at approximately 23:33:10, 23:36:20, and 23:37:35, i.e. $6 \mathrm{~min} 5 \mathrm{~s}$, $2 \operatorname{min~} 55 \mathrm{~s}$, and $1 \mathrm{~min} 40 \mathrm{~s}$ before the end of the seismic records (23:39:15), indicating the increase in the debris flow discharge (Huang et al. 2007, 2008). Correspondingly, there are also three amplitude increase stages (especially on the U-D component) on the synthetic seismograms at approximately 125 , 210 , and $320 \mathrm{~s}$, showing characteristics similar to the actual seismic records, suggesting that numerical computations of seismic signals generated by debris flows can effectively describe features of their movement stages. The seismic amplitude increases in an approximately exponential manner with time, which is partly because of the actual increase in the debris flow mass and partly because of the approaching debris flow with time. The increase in mass by entraining deposited material along the path plays a very important role in the increase in seismic amplitude, as the amplitude would increase at a lower rate if it were caused purely by the approach of the debris flow. In addition, satellite images before 

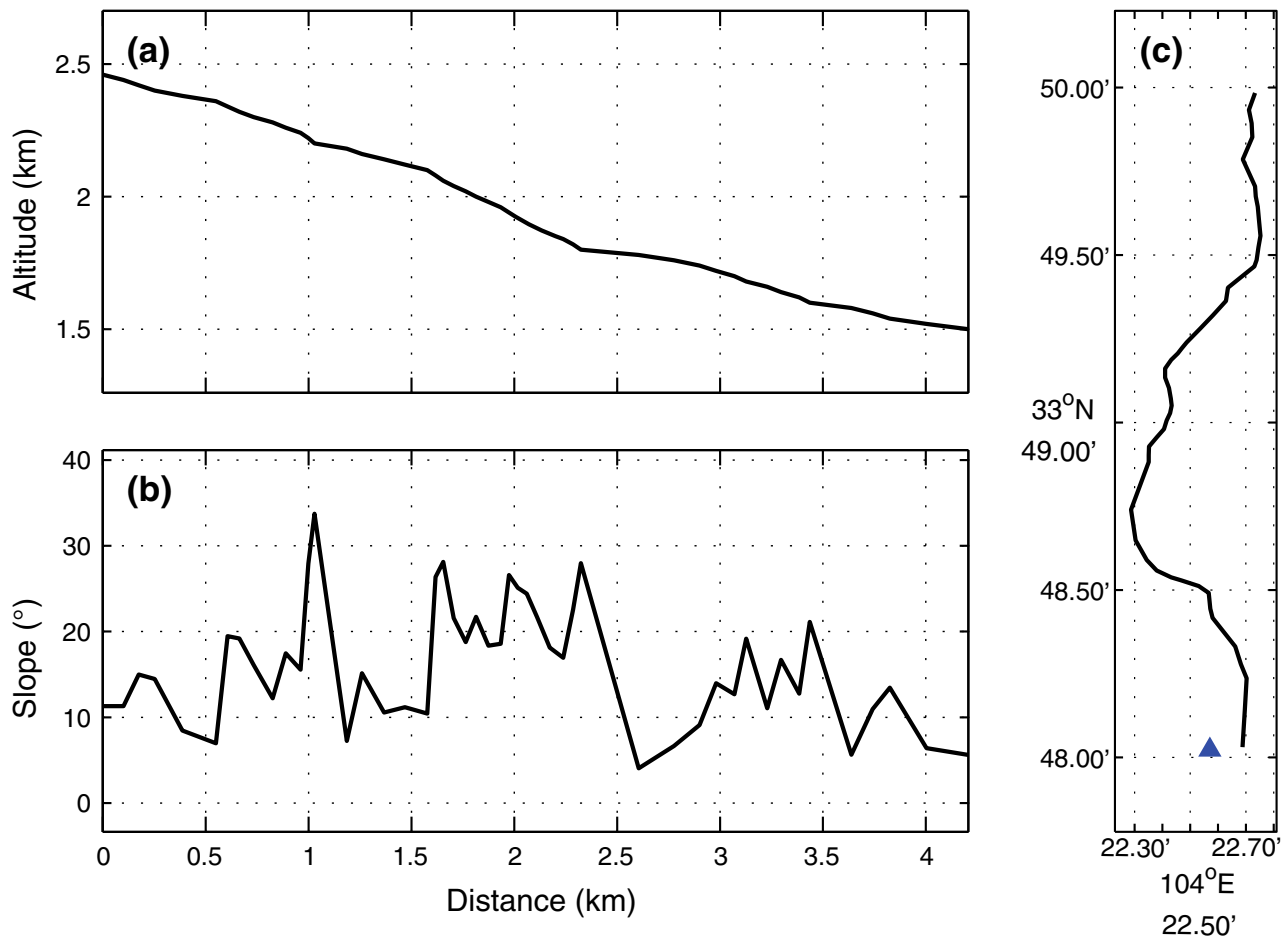

Figure 7

a The altitude along the Sanyanyu gully. b The slope along the Sanyanyu gully. c Shape of the Sanyanyu gully and the location of the ZHQ seismic station
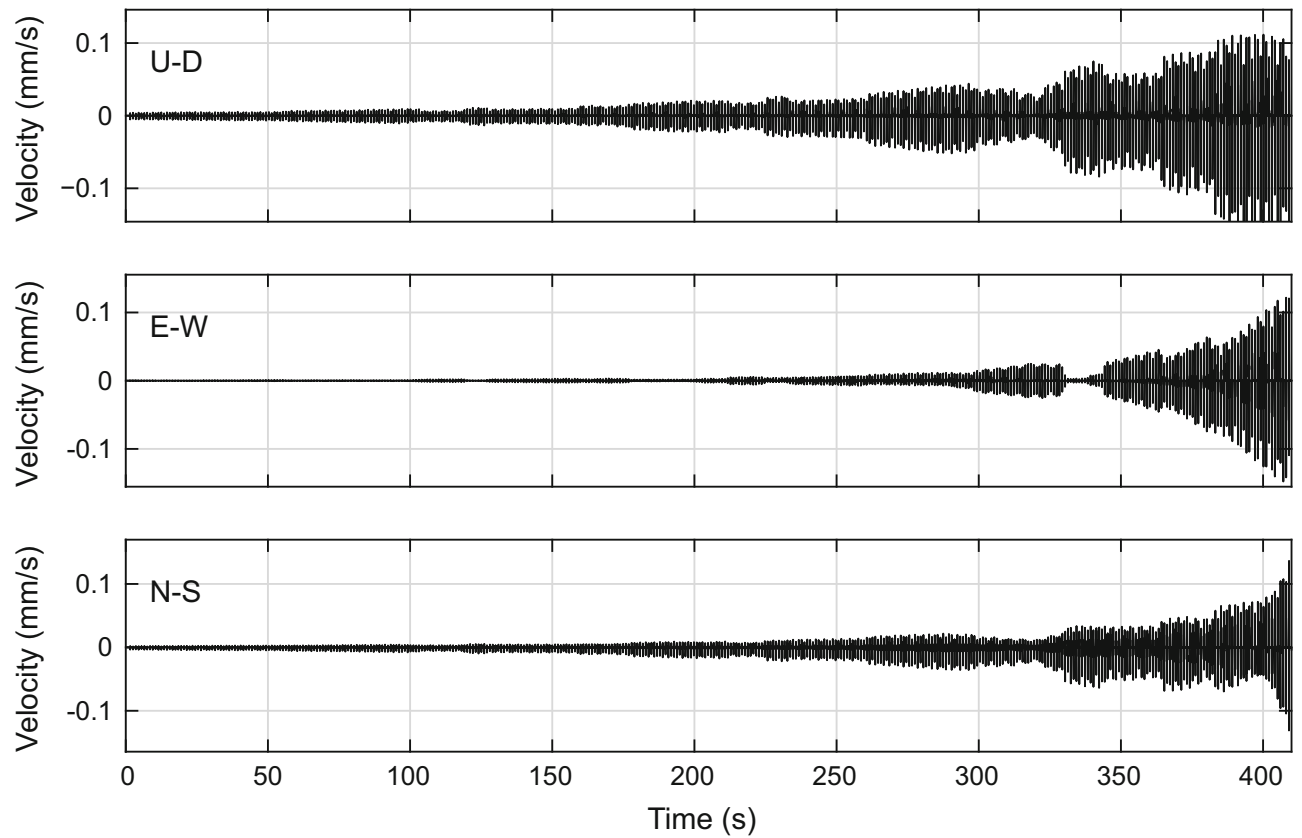

Figure 8

Synthetic seismograms for the Sanyanyu debris flow 
and after the debris flow reveal that the gully was widened significantly (Tang et al. 2011), indicating that additional material was entrained into the flowing mass.

\section{Analyses, Discussion, and Conclusions}

The Zhouqu debris flows, which were induced by heavy rain, resulted in 1765 fatalities and huge economic loss. The ZHQ seismic station is located on the path of the Sanyanyu debris flow to Zhouqu County and recorded the entire debris flow process, providing a good opportunity to analyze characteristics of debris flow seismic signals recorded at a very near field. We find that the energy distribution of seismic signals in the frequency domain can be well represented by a double-exponential model, and the direction of the debris flow can be estimated by analyzing the influence of the Doppler effect on the peak frequency of different components. Stages of the debris flow are well illustrated on spectrograms. Two possible precursors, i.e. a rapid increase in seismic amplitude and a series of signal spikes, are also identified.

The focal mechanism of earthquakes can be well represented by a double-couple model, and the radiation pattern of seismic energy satisfies four-quadrant distribution (Aki and Richards 2002). Seismic sources of large-scale earth surface processes such as landslides and debris flows can be represented by a single-force model, i.e. each component of the source is a time series of force acting on the crust. Seismic signals generated by landslides and debris flows consist of two components: the high-frequency component induced by fractions between the flowing (sliding) material and the boundaries, and the lowfrequency component generated by unloading and reloading of the crust caused by acceleration and deceleration of the bulk movement. The duration of a debris flow is generally longer, and the velocity of a debris flow changes very little after reaching a stable state. Therefore, the seismic source of a debris flow is provided mainly by the frictional force. We modified the debris flow seismic source model by taking only the frictional terms of the force and used a moving point source to calculate synthetic seismograms of the Sanyanyu debris flow. The results are consistent with the field observations in the outlines of seismic amplitude, i.e. the pattern of exponential increase, and three obvious stages of increasing amplitude. Their maximum values are also close.

Seismic signals reveal that there are at least two types of possible precursor characteristics before the formation of the Sanyanyu debris flow: first, a series of signal spikes starting at about 22:50:00; second, about $10 \mathrm{~min}$ before the formation, the seismic amplitude begins to increase rapidly. If we take the features as the precursors of the debris flow, we have at least $15 \mathrm{~min}$ before the debris flow destroys Zhouqu County. If the warning information can be issued to the local residents in time, the number of casualties will be significantly reduced. An efficient debris flow early warning system should be established to prevent such disasters in the future. The system should include at least the following components: First, a small network containing at least three seismic stations should be deployed in a carefully designed location taking into account the local terrain. Second, seismic characteristics in both the time and frequency domains should be monitored in real time. This work is not necessarily carried out at the seismic station; instead, it can be done remotely. Third, a complete information exchange system is needed to ensure that the early warning information obtained from the seismic station can be transmitted to the control center in time and then distributed to the public. This system must be responsive, since the time involved is just tens of minutes. In addition, since geological and geographical features are different for different debris flow gullies, if numerical simulations are performed based on the seismic geological characteristics of each region to obtain the expected seismic response, the results could be very helpful for the early warning system. Other factors, such as rainfall, also need to be considered.

\section{Acknowledgements}

We would like to thank Ruifeng Liu, Zhibin Huang, and Yong Zhao from the China Earthquake Networks Center for their helpful comments on seismic wave 
recognition. We also thank Wenhao Zeng and Yanping Niu from the Lanzhou Institute of Seismology for their kind help in the field investigation. Seismic Analysis Code (SAC, http://ds.iris.edu/files/ sac-manual/) and rdseed (http://ds.iris.edu/ds/nodes/ $\mathrm{dmc} / \mathrm{manuals} / \mathrm{rdseed} /$ ) were used in seismic data processing. The software package Generic Mapping Tools (GMT, http://gmt.soest.hawaii.edu/) was used in preparing figures. Green's functions were calculated using the QSEIS developed by Dr. Rongjiang Wang from GFZ (http://www.gfz-potsdam.de/en/ section/physics-of-earthquakes-and-volcanoes/staff/ profil/rongjiang-wang/). This research is financially supported by the 973 Program 2013CB733200 and the 863 Program 2012AA121302.

Open Access This article is distributed under the terms of the Creative Commons Attribution 4.0 International License (http:// creativecommons.org/licenses/by/4.0/), which permits unrestricted use, distribution, and reproduction in any medium, provided you give appropriate credit to the original author(s) and the source, provide a link to the Creative Commons license, and indicate if changes were made.

Publisher's Note Springer Nature remains neutral with regard to jurisdictional claims in published maps and institutional affiliations.

\section{REFERENCES}

Aki, K., \& Richards, P. G. (2002). Quantitative Seismology: Theory and Methods (2nd ed.). Sausalito: University Science Books.

Arattano, M. (1999). On the use of seismic detectors as monitoring and warning systems for debris flows. Natural Hazards, 20(2-3), 197-213. https://doi.org/10.1023/A:1008061916445.

Burtin, A., Bollinger, L., Cattin, R., \& Vergne, J. (2009). Spatiotemporal sequence of Himalayan debris flow from analysis of high-frequency seismic noise. Journal of Geophysical Research: Earth Surface, 114(F4), F04009. https://doi.org/10.1029/ 2008jf001198.

Burtin, A., Bollinger, L., Vergne, J., Cattin, R., \& Nábělek, J. L. (2008). Spectral analysis of seismic noise induced by rivers: A new tool to monitor spatiotemporal changes in stream hydrodynamics. Journal of Geophysical Research: Solid Earth, 113(B5), B05301. https://doi.org/10.1029/2007JB005034.

Chen, C.-H., Chao, W.-A., Wu, Y.-M., Zhao, L., Chen, Y.-G., Ho, W.-Y., et al. (2013). A seismological study of landquakes using a real-time broad-band seismic network. Geophysical Journal International, 194(2), 885-898. https://doi.org/10.1093/gji/ ggt121.
Cui, P., Wei, F., Xie, H., Yang, K., He, Y., \& Ma, D. (2003). Debris flow and disaster reduction strategies in western china. Quaternary Sciences (in Chinese), 23(02), 142-151.

Dahlen, F. A. (1993). Single-force representation of shallow landslide sources. Bulletin of the Seismological Society of America, 83(1), 130-143.

Dammeier, F., Moore, J. R., Haslinger, F., \& Loew, S. (2011). Characterization of alpine rockslides using statistical analysis of seismic signals. Journal of Geophysical Research: Earth Surface, 116(4), F04024. https://doi.org/10.1029/2011jf002037.

Deparis, J., Jongmans, D., Cotton, F., Baillet, L., Thouvenot, F., \& Hantz, D. (2008). Analysis of rock-fall and rock-fall avalanche seismograms in the French Alps. Bulletin of the Seismological Society of America, 98(4), 1781-1796. https://doi.org/10.1785/ 0120070082.

Ekström, G., Nettles, M., \& Abers, G. A. (2003). Glacial earthquakes. Science, 302(5645), 622-624. https://doi.org/10.1126/ science. 1088057 .

Ekström, G., \& Stark, C. P. (2013). Simple scaling of catastrophic landslide dynamics. Science, 339(6126), 1416-1419. https://doi. org/10.1126/science.1232887.

Fang, H., Cai, Q., Li, Q., Sun, L., \& He, J. (2010). Causes and countermeasures of giant flash flood and debris flow disaster in Zhouqu County in Gansu Province on August 7, 2010. Science of Soil and Water Conservation, 8(6), 14-18+23. (in Chinese).

Feng, Z. Y. (2012). The seismic signatures of the surge wave from the 2009 Xiaolin landslide-dam breach in Taiwan. Hydrological Processes, 26(9), 1342-1351. https://doi.org/10.1002/hyp.8239.

Fukao, Y. (1995). Single-force representation of earthquakes due to landslides or the collapse of caverns. Geophysical Journal International, 122(1), 243-248. https://doi.org/10.1111/j.1365246X.1995.tb03551.x.

Hasegawa, H., \& Kanamori, H. (1987). Source mechanism of the magnitude 7.2 Grand Banks earthquake of November 1929: Double couple or submarine landslide? Bulletin of the Seismological Society of America, 77(6), 1984-2004.

Hibert, C., Ekström, G., \& Stark, C. P. (2014). Dynamics of the Bingham Canyon Mine landslides from seismic signal analysis. Geophysical Research Letters, 41(13), 4535-4541. https://doi. org/10.1002/2014GL060592.

Hibert, C., Mangeney, A., Grandjean, G., \& Shapiro, N. M. (2011). Slope instabilities in Dolomieu crater, Réunion Island: From seismic signals to rockfall characteristics. Journal of Geophysical Research: Earth Surface, 116(F4), F04032. https://doi.org/ 10.1029/2011JF002038.

Huang, X., Li, Z., Yu, D., Xu, Q., \& Su, J. (2018). Dynamic processes of the 24 June 2017 Xinmo landslide in Maoxian revealed by broadband seismic records. Chinese Journal of Geophysics (in Chinese), 61(10), 4055-4062. https://doi.org/10.6038/ cjg2018L0453.

Huang, C. J., Shieh, C. L., \& Yin, H. Y. (2004). Laboratory study of the underground sound generated by debris flows. Journal of Geophysical Research: Earth Surface, 109(F1), F01008. https:// doi.org/10.1029/2003JF000048.

Huang, C.-J., Yeh, C.-H., Chen, C.-Y., \& Chang, S.-T. (2008). Ground vibrations and airborne sounds generated by motion of rock in a river bed. Natural Hazards and Earth System Sciences, 8(5), 1139-1147. https://doi.org/10.5194/nhess-8-1139-2008.

Huang, C. J., Yin, H. Y., Chen, C. Y., Yeh, C. H., \& Wang, C. L. (2007). Ground vibrations produced by rock motions and debris 
flows. Journal of Geophysical Research: Earth Surface, 112(F2), F02014. https://doi.org/10.1029/2005JF000437.

Kanamori, H., \& Given, J. W. (1982). Analysis of long-period seismic waves excited by the May 18, 1980, eruption of Mount St. Helens-A terrestrial monopole? Journal of Geophysical Research: Solid Earth, 87(B7), 5422-5432. https://doi.org/10. 1029/JB087iB07p05422.

Kanamori, H., Given, J. W., \& Lay, T. (1984). Analysis of seismic body waves excited by the Mount St. Helens eruption of May 18, 1980. Journal of Geophysical Research: Solid Earth, 89(3), 1856-1866. https://doi.org/10.1029/jb089ib03p01856.

Kao, H., Kan, C.-W., Chen, R.-Y., Chang, C.-H., Rosenberger, A., Shin, T.-C., et al. (2012). Locating, monitoring, and characterizing typhoon-linduced landslides with real-time seismic signals. Landslides, 9(4), 557-563. https://doi.org/10.1007/s10346-0120322-z.

Li, Z., Huang, X., Xu, Q., Yu, D., Fan, J., \& Qiao, X. (2017). Dynamics of the Wulong landslide revealed by broadband seismic records. Earth, Planets and Space, 69(1), 27. https://doi.org/ 10.1186/s40623-017-0610-x.

Tang, C., Rengers, N., van Asch, T. W. J., Yang, Y. H., \& Wang, G. F. (2011). Triggering conditions and depositional characteristics of a disastrous debris flow event in Zhouqu city, Gansu Province, northwestern China. Natural Hazards and Earth System Sciences, 11(11), 2903-2912. https://doi.org/10.5194/nhess11-2903-2011.

Toksöz, M. N., \& Johnston, D. H. (1981). Seismic wave attenuation (Geophysics reprint series no. 2). Tulsa, Okla: Society of Exploration Geophysicists.
Vilajosana, I., Surinach, E., Abellán, A., Khazaradze, G., Garcia, D., \& Llosa, J. (2008). Rockfall induced seismic signals: case study in Montserrat, Catalonia. Natural Hazards and Earth System Sciences, 8(4), 805-812. https://doi.org/10.5194/nhess-8805-2008.

Wang, R. (1999). A simple orthonormalization method for stable and efficient computation of Green's functions. Bulletin of the Seismological Society of America, 89(3), 733-741.

Yamada, M., Kumagai, H., Matsushi, Y., \& Matsuzawa, T. (2013). Dynamic landslide processes revealed by broadband seismic records. Geophysical Research Letters, 40(12), 2998-3002. https://doi.org/10.1002/grl.50437.

Yu, B., Yang, Y., Su, Y., Huang, W., \& Wang, G. (2010). Research on the giant debris flow hazards in Zhouqu County, Gansu Province on August 7, 2010. Journal of Engineering Geology (in Chinese), 18(4), 437-444.

Zeng, C., Cui, P., Ge, Y., Zhang, J., Lei, Y., \& Yan, Y. (2014). Characteristics and Mechanism of Buildings Damaged by Debris Flows on 11 July, 2013 in Qipangou of Wenchuan, Sichuan. Journal of Earth Sciences and Environment (in Chinese), 36(02), 81-91.

Zhao, J., Moretti, L., Mangeney, A., Stutzmann, E., Kanamori, H., Capdeville, Y., et al. (2015). Model space exploration for determining landslide source history from long-period seismic data. Pure and Applied Geophysics, 172(2), 389-413. https://doi. org/10.1007/s00024-014-0852-5. 